\title{
AUMENTO DE PRODUTIVIDADE DO LRF\#1 DA CSN-PR POR MEIO DA REDUÇÃO DO NÚMERO DE PASSES DE LAMINAÇÃO*
}

\author{
Eduardo Candido de Almeida Wenceslau ${ }^{1}$ \\ Alessandro Rodrigo Ribeiro ${ }^{2}$ \\ Carlos Alberto Martins Ramos ${ }^{3}$ \\ Luciano Gadonski ${ }^{4}$ \\ Matheus Sampaio Modesto de Paula ${ }^{5}$ \\ Wagner Mayer Pedroso 6
}

\section{Resumo}

O laminador reversível 4-HI de uma cadeira da CSN-PR, o LRF\#1 tem capacidade de projeto de 350kton/ano, suficiente para atender a linha de galvanização contínua, LGC, que produz $\circ$ Galvalume $\AA$, primeira unidade no país até sua partida. Deficiências na produtividade desse laminador passaram a ser fator de atenção, pois acarretava na necessidade de complementação de abastecimento de bobinas full hard, $\mathrm{BFH}$, provenientes de outros laminadores do grupo. $\mathrm{O}$ presente trabalho mostra o estudo e plano de ação realizado para incremento da produtividade do laminador, sobretudo por meio da redução do número de passes de laminação e revamp do sistema de refrigeração para atender plenamente a demanda da LGC com baixo custo e possibilitar o fornecimento de BFH a clientes externos.

Palavras-chave:Produtividade; Laminação a frio, Laminador reversível, Redução de passes.

\section{PRODUCTIVITY GROWTH AT THE RCM\#1 BY REDUCING ROLLING PASSES Abstract}

The 4-HI single stand reversing rolding mill at CSN-PR, RCM\#1 has design capacity of $350 \mathrm{kton} / \mathrm{year}$, enough to supply the continuous galvanizing line, CGL, which produces Galvalume, the first and single unit in the country until its launch. Deficiencies in this rolling mill productivity became worth attention, for they caused the need to additionally supply the full hard coils from other rolling mills of the group. This paper work shows the study and action plan undertaken to increase the rolling mill's productivity, mainly by reducing the number of rolling passes through and the cooling system's revamps in order to fully supply CGL's demand in a low cost way and enable full hard coils provision to external customers

Keywords: Reversing Cold Mill, productivity, reduce rolling passes.

1 Engenheiro Eletricista, Coordenador de Laminação, Gerência de Laminação e Galvanização da Companhia Siderúrgica Nacional, Araucária, Paraná, Brasil.

2 Engenheiro Mecânico, Engenheiro de Desenvolvimento Sr., Gerência de Laminação e Galvanização da Companhia Siderúrgica Nacional, Araucária, Paraná, Brasil.

3 Técnico Mecânico, Técnico de Desenvolvimento Especialista, Gerência de Manutenção e Utilidades da Companhia Siderúrgica Nacional, Araucária, Paraná, Brasil.

4 Engenheiro de Produção, Engenheiro de Desenvolvimento Pl., Gerência de Laminação e Galvanização da Companhia Siderúrgica Nacional, Araucária, Paraná, Brasil.

5 Engenheiro de Materiais, Engenheiro de Desenvolvimento Pl.,Coordenação Técnica da Qualidade da Companhia Siderúrgica Nacional, Araucária, Paraná, Brasil.

6 Engenheiro Mecânico, Coordenador de Decapagem, Gerência de Laminação e Galvanização da Companhia Siderúrgica Nacional, Araucária, Paraná, Brasil.

\footnotetext{
* Contribuição técnica ao $51^{\circ}$ Seminário de Laminação - Processos e Produtos Laminados e Revestidos, 28 a 31 de outubro de 2014, Foz do Iguaçu, PR, Brasil.
} 


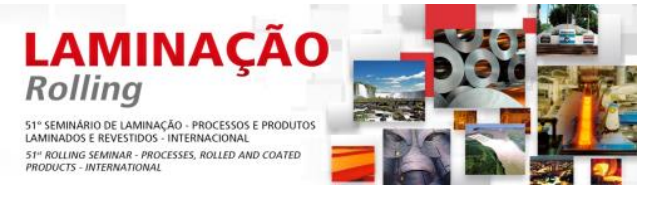

\section{INTRODUÇÃO}

A planta da CSN, localizada em Araucária/PR, começou sua produção em $2000 \mathrm{com}$ a entrada em operação do Centro de Serviços. Em 2003 as linhas de Decapagem, Laminação a Frio, Galvanização Contínua e Pintura Contínua entraram em operação. O principal foco da planta no Paraná é atender aos mercados de linha branca e construção civil. Era a única planta no Brasil a produzir o Galvalume ${ }^{\circledR}$. A implantação da fábrica no Paraná faz parte da estratégia da empresa de ampliar seus negócios e de se aproximar de seus principais clientes.

Os laminadores reversíveis apresentam uma boa alternativa para o processo de laminação a frio de aços planos, principalmente, devido ao investimento inicial mais baixo quando comparado aos laminadores de 4 ou 5 cadeiras. Porém, a produtividade desses laminadores reversíveis passa a ser um fator que exige bastante atenção e estudo, porque a espessura final é conseguida com uma sequência de passes, logo, para uma mesma espessura final, quanto maior for a espessura a quente, maior será o número de passes aplicados e consequentemente, menores será a produtividade. Uma decisão óbvia é a de utilizar menores espessuras a quente, e então, reduzir o número de passes e aumentar a produtividade, contudo, essa prática levaria à redução na produtividade da laminação a quente e decapagem.

O laminador reversível 4-HI de uma cadeira da CSN-PR entrou em produção em dez/2003, com um mix médio esperado de espessuras acima de 0,45 mm. A capacidade de projeto do LRF\#1 é de 350kton/ano, suficiente para abastecer a LGC, com 330kton/ano de capacidade. Contudo, a partir de 2006, depois de decorrido os anos iniciais da curva de aprendizado, a LGC e o LRF não vinham apresentando a mesma capacidade produtiva, conforme era a expectativa do projeto. Assim, deficiências na produtividade desse laminador passaram a ser fator de atenção.

Este trabalho mostra o estudo e plano de ação realizado entre outubro de 2011 e meados de 2013 para incremento da produtividade do laminador, principalmente com a otimização de estratégias de laminação e medidas para redução do número de arrebentamentos, atingindo assim plena capacidade de fornecimento de BFH's para LGC com menor custo.

\section{MATERIAIS E MÉTODOS}

A definição do problema a ser trabalhado foi o ponto inicial do projeto. A questão principal era 0 volume de produção disponibilizado pelo laminador inferior à necessidade da linha de galvanização. Sabemos que o volume de produção é função de dois fatores basicamente: Tempo de máquina operando - Utilização; e peso produzido por unidade de tempo - Produtividade.

Analisando o cenário neste sentido, tomamos como base a produção de mix de espessuras padrões para o laminador para analisar os fatores utilização e produtividade. Olhado o relatório gerencial de produção do dia 16/10/11, que foi laminado praticamente apenas material com a dimensão padrão de $0,37 \times 1200 \mathrm{~mm}$, vimos que foram processadas 740 ton com índice de utilização da linha de $82,2 \%$, valor de utilização razoável para um laminador reversível e acima da meta esperada de $77 \%$. No entanto, foi verificado que o resultado de produção da linha estava abaixo do necessário para atendimento da LGC. Neste cenário, avaliamos que mesmo em condições boas de utilização da linha o ponto central a ser trabalhado era a produtividade.

\footnotetext{
* Contribuição técnica ao $51^{\circ}$ Seminário de Laminação - Processos e Produtos Laminados e Revestidos, 28 a 31 de outubro de 2014, Foz do Iguaçu, PR, Brasil.
} 
$\mathrm{Na}$ figura 1 é mostrado o cenário da produtividade do material padrão, correspondente a $80 \%$ do mix de produção médio processado no laminador durante o período que antecedeu 0 início deste trabalho. $O$ valor de produtividade do material $0,37 \times 1200 \mathrm{~mm}$ estava em torno de $37 \mathrm{ton} / \mathrm{h}$ e do $0,44 \times 1200 \mathrm{~mm}$ em $42 \mathrm{ton} / \mathrm{h}$. Alguns meses antes do trabalho houve queda de produtividade do material $0,44 \times 1200 \mathrm{~mm}$ devido aumento da espessura de entrada da $B Q$ de $2,26 \mathrm{~mm}$ para $2,40 \mathrm{~mm}$, o que adicionou um passe ao processo de laminação, reduzindo ainda mais a sua produtividade.

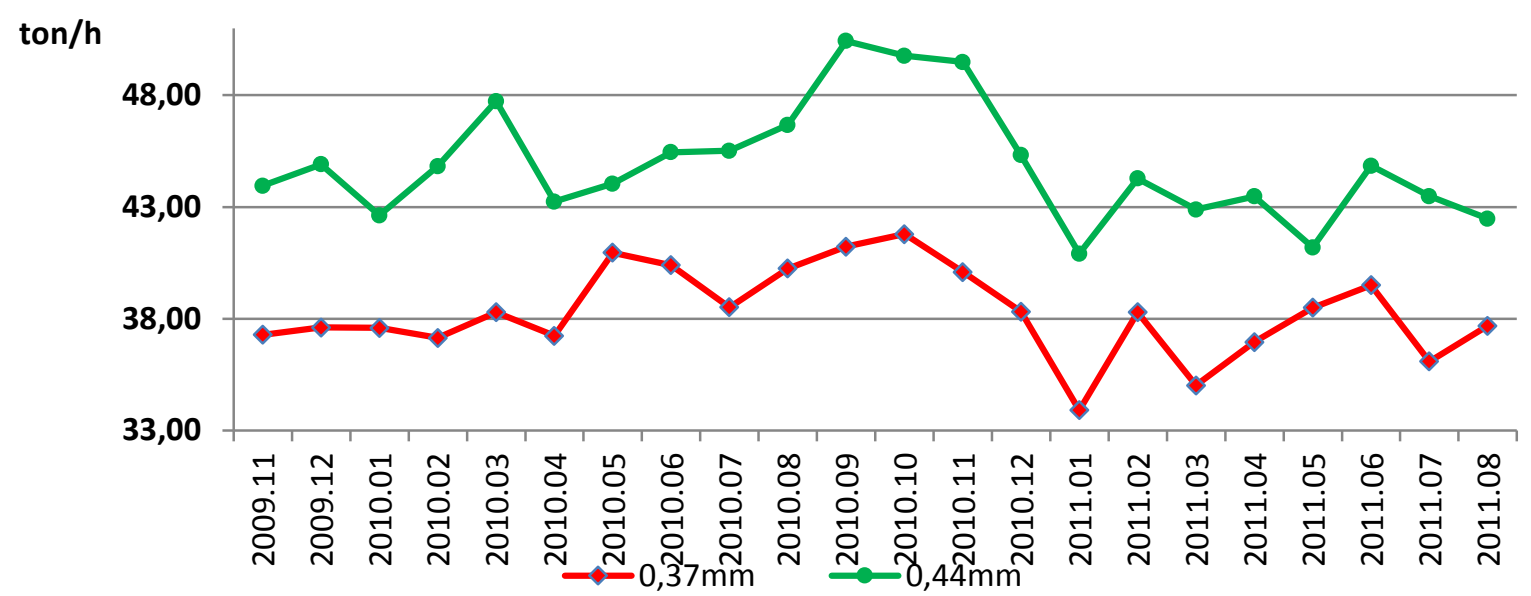

Figura 1. Produtividade média dos matérias padrão para o LRF\#1.

Nesta fase, até outubro de 2011, todo o material padrão era processado em 5 passes, e o resultado da produção era como mostrado na figura 2. Como se pode perceber estava bem aquém da produção da LGC. Todo o déficit de produção entre as linhas era suprido por material proveniente de outros laminadores do grupo. Em casos extremos podia ocorrer a parada da LGC por falta de material.

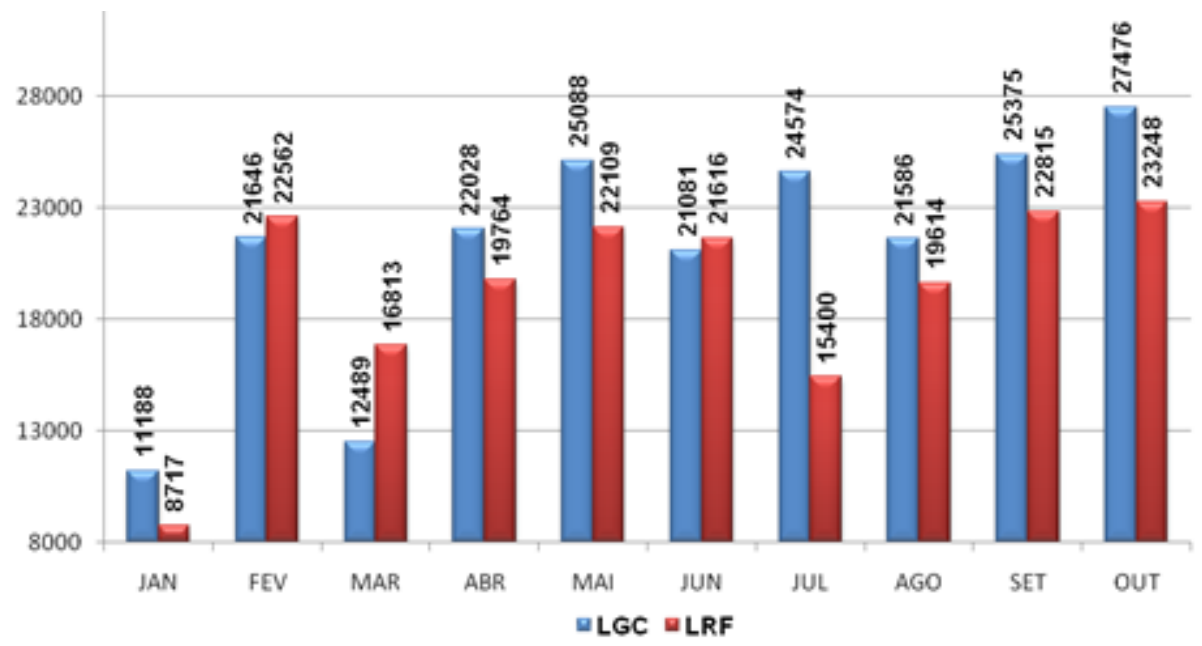

Figura 2. Atendimento do programa de produção em toneladas LGC x LRF em 2011

Com o problema definido a metodologia de trabalho adotada foi o PDCA. A primeira etapa do projeto PDCA é o planejamento, conforme ilustrado na figura 3, no qual se devem determinar as variáveis de maior impacto para então aprofundar-se de forma a atuar nos pontos em que estão os maiores limitantes à produtividade e 


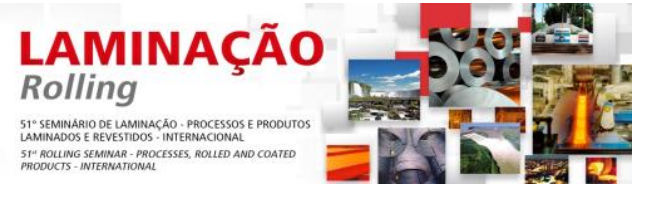

consequentemente as oportunidades para melhoria do desempenho operacional da linha. A segunda etapa então é a execução do plano de ação desenhado com base no planejamento, atacando os pontos levantados durante a primeira etapa. Após a execução das ações os resultados são avaliados na terceira etapa, a de checagem, para então as ações do trabalho se tornarem padrão, fechando assim o ciclo PDCA.

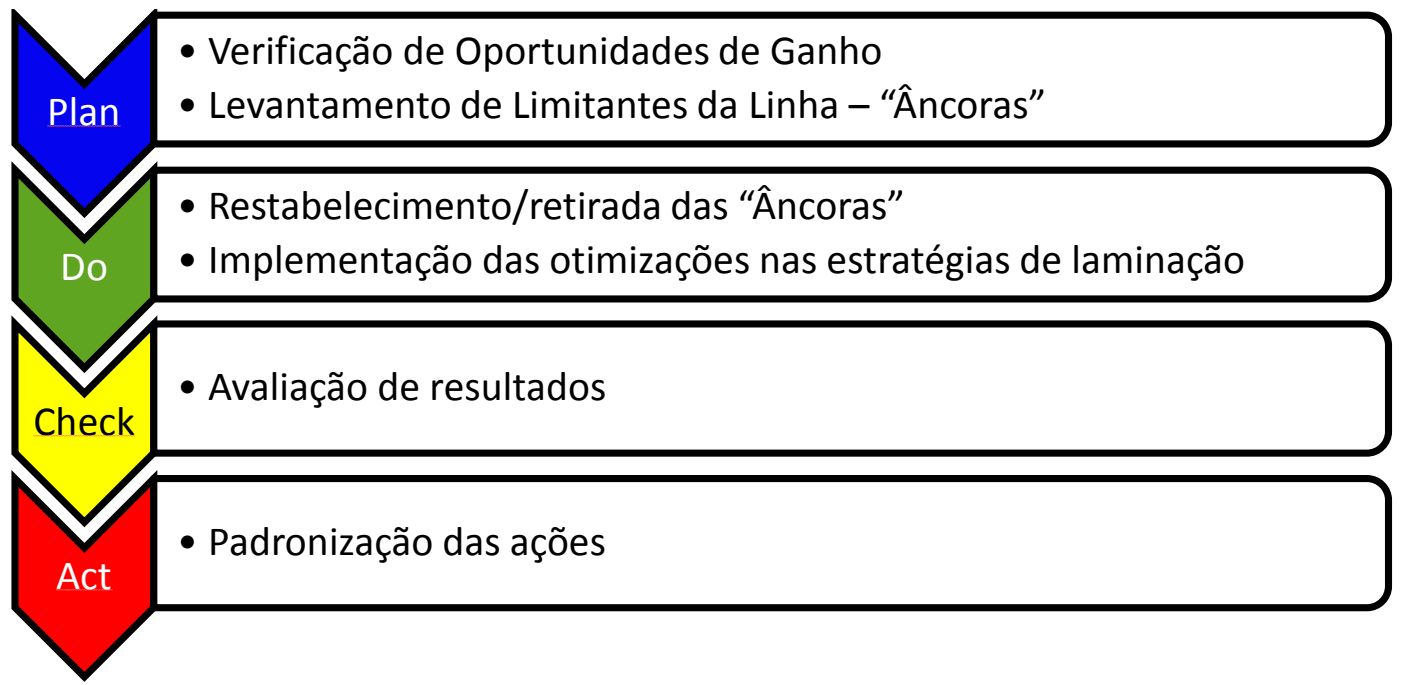

Figura 3. Estrutura do trabalho - PDCA

\subsection{PLANEJAMENTO}

\subsubsection{Verificação de oportunidades de ganho de produtividade}

No laminador reversível avaliamos ser possível aumentar a produtividade de quatro maneiras, conforme ilustrado na Figura 4: aumentando-se a velocidade de laminação, reduzindo-se o número de passes, aumentando a aceleração e melhorando-se os tempos de encaixe. Considerando as possibilidades, avaliamos que os tempos de encaixe já eram controlados e estavam otimizados e a aceleração é limitada pela capacidade dos acionamentos dos motores. Assim, a oportunidade era reduzir o número de passes sem reduzir a velocidade, portanto, foi proposta a readequação nas estratégias de laminação para laminação em 4 passes.

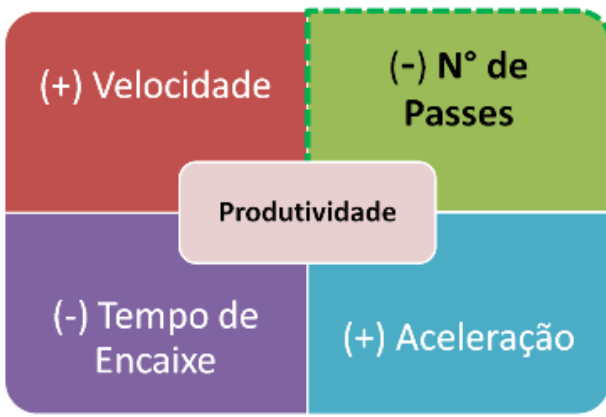

Figura 4. Oportunidades de ganho de produtividade

Para isto, são determinadas novas reduções para cada passe levando-se em consideração a máxima potência do motor da cadeira de laminação e a distribuição

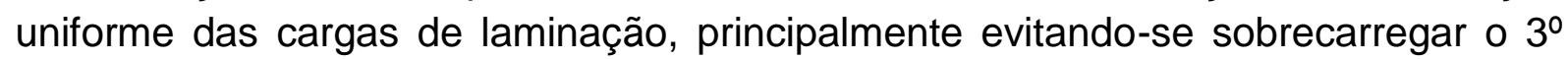

* Contribuição técnica ao $51^{\circ}$ Seminário de Laminação - Processos e Produtos Laminados e Revestidos, 28 a 31 de outubro de 2014, Foz do Iguaçu, PR, Brasil. 


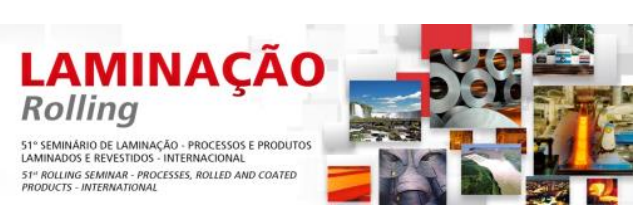

passe, pois é nele que ocorrem as maiores temperaturas de laminação e também a geração dos arranhados sempre que as cargas de laminação superam valores aceitáveis. Contudo, para que a redução em um passe fosse possível mantendo-se a qualidade das bobinas, era necessário primeiramente remover as âncoras que limitavam a velocidade do laminador, caso contrário a velocidade teria que ser reduzida a tal ponto que anularia o potencial ganho de produtividade através da redução de um passe de laminação.

\subsubsection{Levantamento de limitantes da linha - "Âncoras"}

- Problemas térmicos sistema de emulsão

Caso fossem tão somente alteradas as estratégias de laminação de 5 para 4 passes, sem melhorias no sistema de refrigeração, os arranhados de refrigeração seriam extremamente intensos a tal ponto que não seriam cobertos pelo revestimento 55\%AI-Zn da LGC. Portanto, foi necessário ajustá-lo para atender a esta nova necessidade.

- Deficiência no sistema de refrigeração e arranhados na tira

Além do fato da temperatura da emulsão estar inapropriada, havia também o problema da falta de pressão e limitação de vazão do sistema de emulsão do LRF. Mesmo com o sistema de refrigeração, até em certo ponto, em condições corretas de operação, o arranhado na face inferior inviabilizaria a redução de passes de laminação mantendo as velocidades de processo.

- Rolo medidor de planicidade da reversível 1

O rolo da entrada estava avariado e seus sensores estavam apresentando medições aleatórias. Assim, somente seria possível laminar com número par de passes depois de restabelecida a funcionalidade deste equipamento, além de estabelecimento de um plano de ações para evitar que falhasse novamente.

- Aquecimento nos mancais de cilindros de encosto

Os aquecimentos nos mancais de cilindros de encosto eram frequentes durante a laminação, havia redução de velocidade ou mesmo parada de processo no último passe gerando problemas de qualidade na $\mathrm{BFH}$, como anomalias na planicidade e espessura, e comprometimento da produtividade devido à perda de tempo nas desacelerações e paradas de linha para normalização de temperatura.

\subsection{EXECUÇÃO}

\subsubsection{Restabelecimento/retirada das âncoras}

- Restabelecimento shapemeter de entrada

O restabelecimento do shapemeter de entrada se deu por meio da atuação da equipe de manutenção da linha em conjunto com a equipe de automação e instrumentação da unidade. Para tanto foi necessário desenvolver duas frentes de trabalho: uma mecânica e outra eletrônica. As análises e ações executadas foram praticadas no período de julho/2011 a meados de outubro/2011, quando a função do equipamento foi restabelecida. Além disso, ações de melhoria e garantia da 


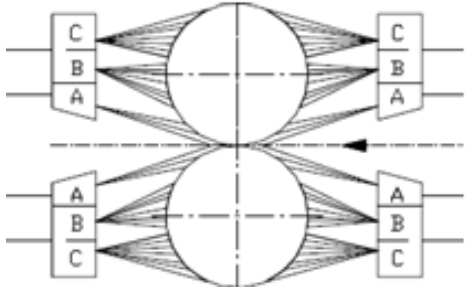

Figura 5. Disposição das linhas de refrigeração

Durante toda a extensão do trabalho foram executadas alterações e ajustes nas configurações das linhas de bicos e setpoints de pressão para extrair o máximo de resultado do sistema. Finalmente, na metade de 2012, chegou-se a seguinte configuração de bicos:

- Linha A e B abertos somente na faixa de $1200 \mathrm{~mm}$ de largura;

- Linha $C$ superior fechada;

- Linha C inferior, abertos 18 bicos;

- Pressão máxima na bomba de alimentação e 5 bar nos manifold.

Como resultado foi alcançado quase $40 \%$ de vazão na linha $A$ e vazão total do sistema otimizada para a região efetiva de laminação e dentro dos limites do sistema. O quadro comparativo entre a configuração original de projeto, situação antes do trabalho e após ajustes está mostrado na figura 6. Com a configuração ajustada foi possível alcançar velocidades limitadas pouco inferiores à potência do motor e com arranhados de intensidade leve somente na face inferior.

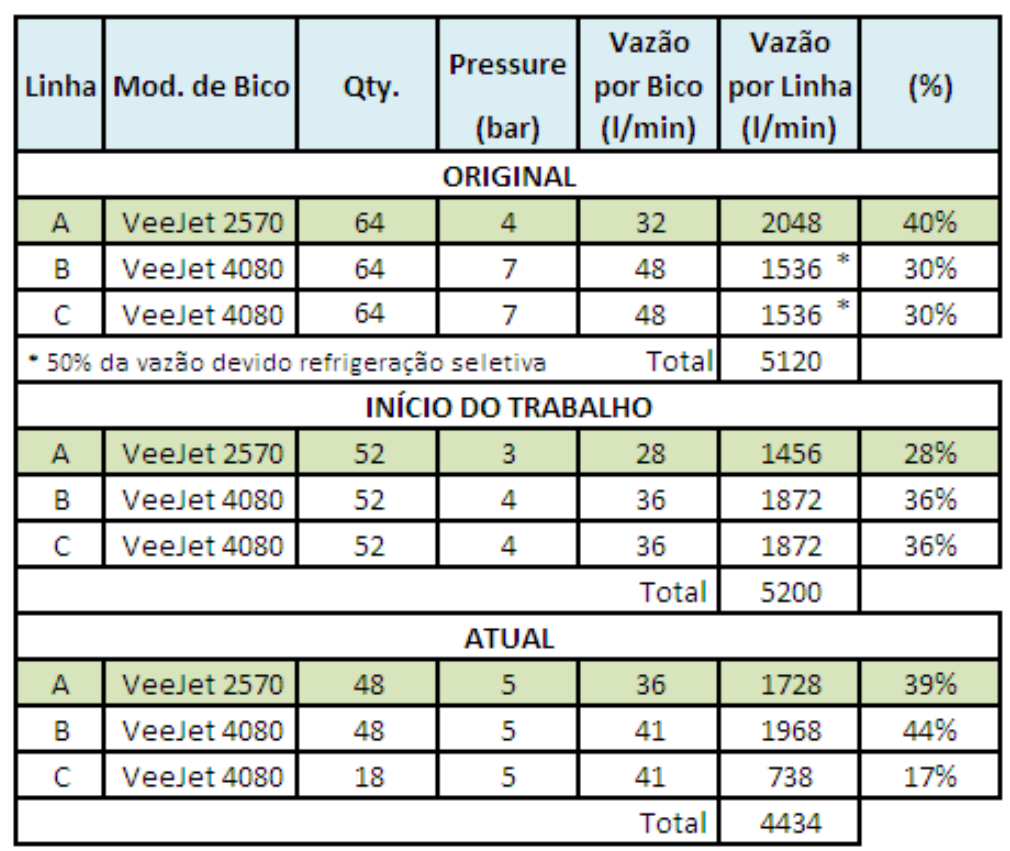

Figura 6. Configuração das linhas de bicos de refrigeração.

- Posterior modernização no sistema de refrigeração

Com os ajustes implantados no sistema de refrigeração ficou clara a necessidade de modernização no sistema para garantir e sustentar a redução do número de passes. Em paralelo ao período de adequação das estratégias de laminação foi desenvolvida 


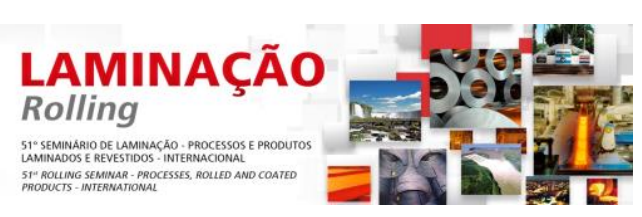

a contratação de uma modernização no sistema de refrigeração. As premissas para o desenvolvimento do projeto foram:

- Garantia de ângulos de bicos e alinhamento dos manifolds

- Manutenabilidade

- Seccionamento

- Estanqueidade

- Suscetibilidade a entupimentos

- Readequação de vazão

As soluções para atendimento do sistema se deu em parceria com o fornecedor, onde chegamos a conclusão da adoção de filtros individuais para cada bico para melhorar questões de entupimentos, retenção em caba bico para solucionar questão de estanqueidade, construção de manifold seccionado na largura de 1200mm e adoção de válvulas de alimentação independentes para acionamento somente quando necessário, sedes fixas com posicionamento e angulações fixas dos bicos para garantir correto direcionamento da refrigeração e lubrificação de processo e por fim, sistema de bicos com fácil manutenção para melhorar questões operacionais de limpeza e intervenção no sistema.

Para as questões térmicas de determinação de vazões e abrangência da refrigeração, que determinariam o desing final do sistema foi gerado um estudo em CFD do laminador, figura 7, bem como as características de processo para estudo da melhor disposição física e adoção dos bicos mais adequados para o processo.
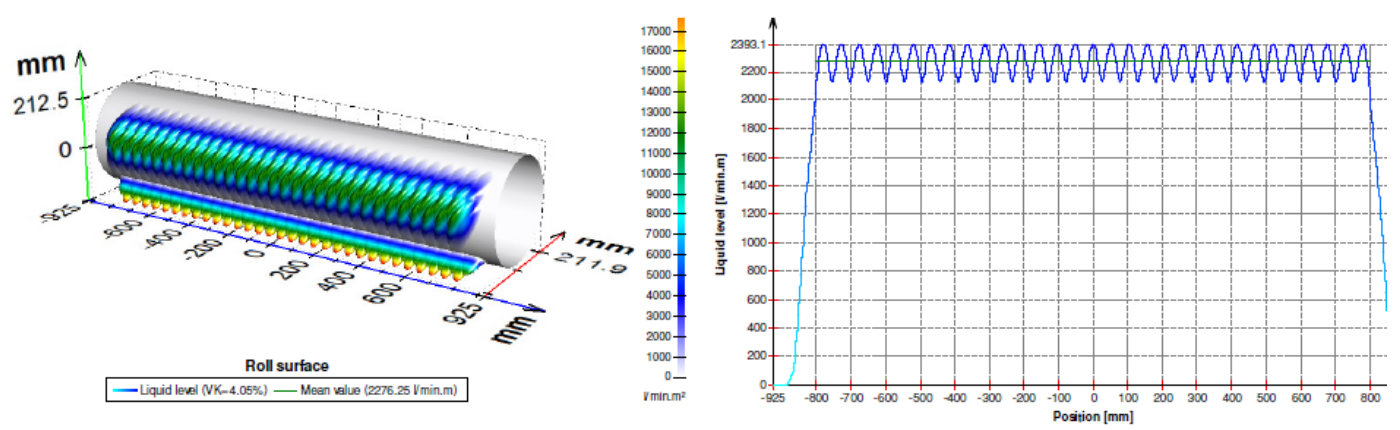

Figura 7. Estudo CFD para determinação do desing do sistema de refrigeração

O relatório final do estudo mostrou a configuração ilustrada na figura 8 como referência para o projeto dos chuveiros. Com os resultados obtidos por meio dos ajustes no sistema antigo, foi possível criticar a proposta no quesito da vazão na linha de refrigeração básica. A questão de troca térmica com os cilindros estava de acordo, porém achamos adequado aumentar a vazão na linha $A$ para melhorar a questão dos arranhados de refrigeração. Assim, na linha $A$, ao invés de utilizar o bico VeeJet® 2570 ( $25^{\circ}$ de abertura do leque e $\left.70 \mathrm{l} / \mathrm{min}\right)$, foi planejado a utilização de um bico de mesma cobertura porém com maior vazão, o VeeJet® 2590. E nas linhas B e C foi consensado a aplicação de bicos VeeJet XT 8080. 


\begin{tabular}{|c|c|c|c|c|c|}
\hline Line & Nozzle model & Qty. & $\begin{array}{c}\text { Pressure } \\
\text { (bar) }\end{array}$ & $\begin{array}{c}\text { Flowrate per } \\
\text { nozzle } \\
(\text { Vmin) }\end{array}$ & $\begin{array}{c}\text { Total flowrate } \\
(\text { Vmin) }\end{array}$ \\
\hline A & VeeJet 2570 & 24 & 3,5 & 30 & 720 \\
\hline B & VeeJet XT 8090 & 16 & 4,0 & 40 & 640 \\
\hline C & VeeJet XT 8090 & 16 & 4,0 & 40 & 640 \\
\hline \multicolumn{7}{|c|}{ Total - 1 header } & 2000 \\
\hline \multicolumn{7}{|c|}{ Total - 2 headers } & 4000 \\
\hline
\end{tabular}

Figura 8. Proposta inicial após estudo CFD da refrigeração

Consolidadas as especificações do novo sistema foi construído pelo fornecedor e instalado no laminador em duas etapas, sendo dezembro de 2012 e janeiro de 2013. O que alavancou ainda mais os valores de produtividade.

Ainda durante esse processo foi levantado junto ao fornecedor de óleo a necessidade de ajustar o insumo à nova condição de processo. O óleo deveria ser melhorado para suportar as cargas mais altas de laminação geradas pela redução do número de passes de laminação. Para tanto o fornecedor fez a seleção de aditivos de extrema pressão - aditivos EP - e incorporou na mesma base do óleo já utilizado e então foi realizado o teste do insumo em março/2012 com aprovação.

\subsubsection{Implementação das otimizações nas estratégias de laminação}

As otimizações das estratégias, ou plano de reduções, foram ajustadas com as variáveis: - Taxa de redução - velocidade de laminação - tensões avante e à ré parâmetros da emulsão. Os ajustes foram determinados visando não ultrapassar máxima potência dos motores, temperatura crítica de laminação e qualidade superficial na questão de arranhados por falha de refrigeração.

Uma vez restabelecido o shapemeter de entrada e controlada a temperatura da emulsão, que caiu de $60 \mathrm{C}$ para $48 \mathrm{C}$ após o restabelecimento do trocador de calor, tivemos uma boa oportunidade para realizar os teste de redução de passes.

A princípio foi realizado teste de laminação em 4 passes do material 2,4mm para $0,44 \times 1200 \mathrm{~mm}$ no dia $17 / 10 / 11$. Foi criada uma estratégia com reduções de $38 \%$, $32 \%, 32 \%$ e $32 \%$. Não houve problemas de atingimento de espessura, aumento demasiado de força ou sobre temperatura. As temperaturas ficaram da seguinte forma: $-1^{\circ}$ passe $-60^{\circ} \mathrm{C},-2^{\circ}$ passe $-105^{\circ} \mathrm{C},-3^{\circ}$ passe $-122^{\circ} \mathrm{C}$, - $4^{\circ}$ passe $117^{\circ} \mathrm{C}$.

Dia $19 / 10 / 11$ foi testada a laminação do $2,1 \mathrm{~mm}$ para $0,37 \mathrm{~mm}$. Foi reduzida a rugosidade dos cilindros de trabalho de 0,7 para 0,6umRA para diminuir o atrito no arco de contato. Com isto, a temperatura no 30 passe neste material em 5 passes estava com apenas $103^{\circ} \mathrm{C}$, condições ideais para realizar o teste de 4 passes. Neste caso a distribuição de reduções foi diferente, para evitar problemas de fora de bitola ao reduzir demasiadamente no último passe. Foi criada uma estratégia com reduções de $40 \%, 38 \%, 38 \%$ e $23 \%$. A temperatura máxima obtida foi de $120^{\circ} \mathrm{C}$ a $1167 \mathrm{~m} / \mathrm{min}$ no $3^{\circ}$ passe.

Depois dos primeiros testes foram executadas diversas ações de ajustes no equipamento e otimizações nas estratégias de laminação para alcançarem as melhores performances de produtividade e qualidade. As principais alterações foram:

- Criação de estratégias para laminação em 4 passes;

* Contribuição técnica ao $51^{\circ}$ Seminário de Laminação - Processos e Produtos Laminados e Revestidos, 28 a 31 de outubro de 2014, Foz do Iguaçu, PR, Brasil. 
- Parametrização de acesso às estratégias criadas;

- Redistribuição de reduções entre passes;

- Adequação de tensões avante e à ré para obtenção de maiores velocidades e redução do risco de arrebentamentos;

- Parametrização de limitadores no modelo matemático do nível 2;

- Ajustes nas curvas de planicidade;

- Adequação dos parâmetros de emulsão;

- Programação para desaceleração automática em caso de corrente do motor principal ultrapasse $100 \%$ do nominal;

- Revisão de procedimentos operacionais e treinamento com a equipe operacional; Após a execução de todos os ajustes e ações citadas acima resultaram em duas estratégias de laminação mostradas na figura 8.

\begin{tabular}{|c|c|c|c|c|c|c|}
\hline \multicolumn{7}{|c|}{ Estratégia $\mathrm{n}^{\circ} 8 \rightarrow>$ materiais $0,37 \mathrm{~mm}$} \\
\hline \multirow{2}{*}{ Passe } & \multirow{2}{*}{\begin{tabular}{|c|} 
Redução \\
Relativa (\%)
\end{tabular}} & \multicolumn{2}{|c|}{ Espessura $(\mathrm{mm})$} & \multirow{2}{*}{$\begin{array}{c}\text { Velocidade } \\
\text { (m/min) }\end{array}$} & \multicolumn{2}{|c|}{ Tensão (N/mm2) } \\
\hline & & Entrada & Saída & & Entrada & Saída \\
\hline 1 & 40 & 2,1 & 1,258 & 450 & 40 & 90 \\
\hline 2 & 38 & 1,258 & 0,78 & 900 & 95 & 145 \\
\hline 3 & 35 & 0,78 & 0,507 & 1150 & 140 & 140 \\
\hline 4 & 26.4 & 0,507 & 0,373 & 1300 & 175 & 60 \\
\hline
\end{tabular}

\begin{tabular}{|c|c|c|c|c|c|c|}
\hline \multicolumn{7}{|c|}{ Estratégia $\mathrm{n}^{0} 7 \rightarrow$ materiais $0,44 \mathrm{~mm}$} \\
\hline \multirow{2}{*}{ Passe } & \multirow{2}{*}{\begin{tabular}{|c|} 
Redução \\
Relativa (\%)
\end{tabular}} & \multicolumn{2}{|c|}{ Espessura $(\mathrm{mm})$} & \multirow{2}{*}{$\begin{array}{c}\text { Velocidade } \\
\text { (m/min) }\end{array}$} & \multicolumn{2}{|c|}{ Tensão (N/mm2) } \\
\hline & & Entrada & Saída & & Entrada & Saída \\
\hline 1 & 38 & 2,4 & 1,526 & 400 & 40 & 75 \\
\hline 2 & 35.4 & 1,526 & 0,985 & 800 & 75 & 120 \\
\hline 3 & 35.4 & 0,985 & 0,636 & 1050 & 120 & 165 \\
\hline 4 & 30.5 & 0,636 & 0,442 & 1300 & 165 & 70 \\
\hline
\end{tabular}

Figura 8. Estratégias atuais de 4 passes para materiais padrão

\section{RESULTADOS}

A data a ser considerada para as análises do tipo antes $V$ s depois é $25 / 10 / 11$, pois foi quando o processamento em 4 passes se tornou padrão operacional. $E \quad 0$ segundo período a ser considerado é janeiro/2013, após a modernização do sistema de refrigeração quando foi possível incrementar as velocidade máximas de processo.

As produtividades máximas dos materiais $0,44 \mathrm{~mm}$ e $0,37 \mathrm{~mm}$ aumentaram conforme ilustrado na figura 9 após período da adoção de 4 passes. Após o revamp do sistema de refrigeração, janeiro/2013 ainda foi possível incrementar em média 5,8\% na produtividade média dos materiais padrão.

Além disso, houve outros ganhos associados ao trabalho:

- Produtividade média: pode ser medida pelo índice de eficiência da linha, que mostra a produtividade real comparada com a produtividade programada esperada, que subiu de $102 \%$ em setembro/2011 para aproximadamente $120 \%$ no $3^{\circ}$ trimestre/2012, conforme figura 10. 

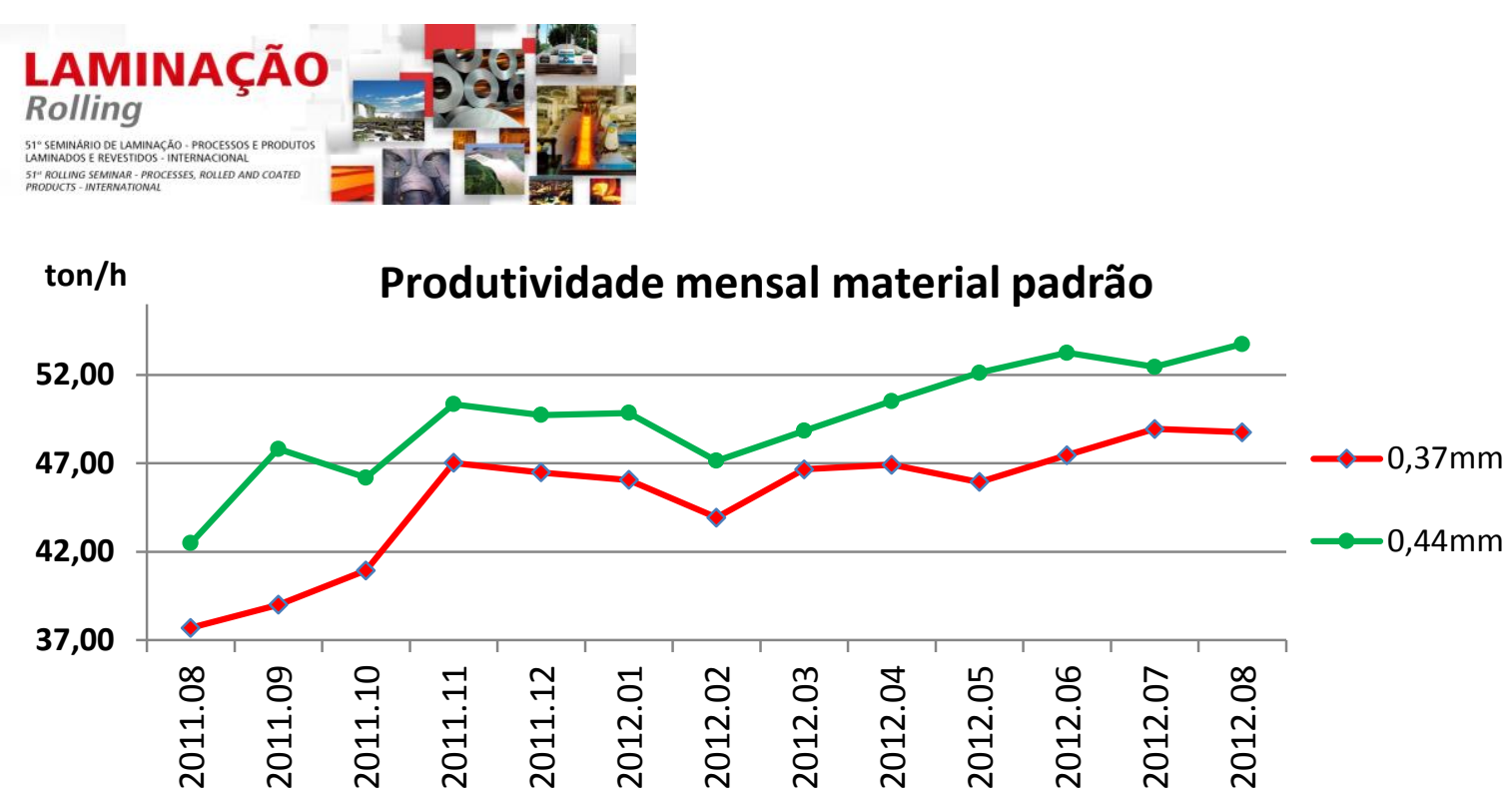

Figura 9. Resultado de ganho de produtividade material 0,37 e $0,44 \mathrm{~mm}$

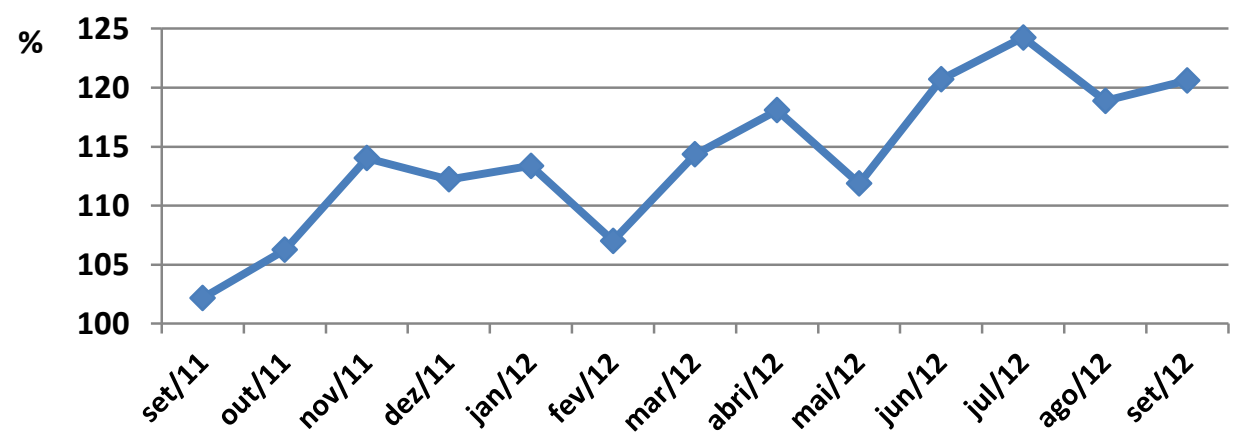

Figura 10. Evolução de eficiência do laminador

- Consumo de cilindro de trabalho: A tonelagem produzida por quilômetro laminado ficou menor, sendo possível estender as campanhas em praticamente duas bobinas. A tabela 1 mostra os comprimentos por passe, em metros, considerando uma bobina de peso médio de 20 toneladas e campanha de $150 \mathrm{~km}$. Tanto no material $0,37 \mathrm{~mm}$ quanto no $0,44 \mathrm{~mm}$ o ganho de extensão de campanha maior que $20 \%$. Além disso, há de se considerar que em trocas programadas o consumo na retífica será o mesmo com uma produção $20 \%$ maior e também haverá menos paradas de máquina para trocas de cilindros, gerando ganhos em consumo de cilindros e utilização da linha.

\begin{tabular}{r|r|r|r|r|} 
& \multicolumn{2}{|c|}{$2, \mathbf{1 - > 0 , 3 7 m m}$} & \multicolumn{2}{c|}{$2, \mathbf{4}->0,44 \mathrm{~mm}$} \\
\cline { 2 - 5 } & 4 passes & 5 passes & 4 passes & 5 passes \\
\hline $1^{\circ}$ passe & 1.687 & 1.656 & 1.391 & 1.327 \\
\hline $2^{\circ}$ passe & 2.722 & 2.353 & 2.155 & 1.846 \\
\hline $3^{\circ}$ passe & 4.187 & 3.343 & 3.338 & 2.654 \\
\hline $4^{\circ}$ passe & 5.692 & 4.750 & 4.803 & 3.731 \\
\hline $5^{\circ}$ passe & - & 5.692 & & 4.803 \\
\hline Total & 14.288 & 17.794 & 11.687 & 14.361 \\
\hline Bob/Campanha & & & & 10,4 \\
\hline Diferença & 10,5 & 8,4 & 12,8 & 10 \\
\hline
\end{tabular}

Tabela 1. Quadro comparativo de bobinas por campanha de cilindro 
- Tempos de encaixe: Ficaram menores, em média, 26 segundos a menos por bobina, o que implica em aproximadamente 18 minutos por dia, quase o suficiente para produzir uma bobina a mais. Isto ocorre porque quando a bobina é processada em 4 passes, ela é retirada pela enroladeira de entrada ao mesmo tempo em que a próxima bobina é encaixada na enroladeira de saída.

\section{CONCLUSÃo}

Entre 2006 e 2011, a LGC produziu sempre em torno de 20.000 toneladas anuais a mais que o LRF, sendo, portanto, necessária a complementação deste abastecimento a partir de outros laminadores a frio do grupo CSN, que nem sempre tinham disponibilidade para esta entrega, até porque tal complementação não era previsto. Além disso, como os demais laminadores estão na planta Usina Presidente Vargas, na cidade de Volta Redonda-RJ, o tempo de trânsito das bobinas implicava na perda de flexibilidade do planejamento de produção para atendimento mais ágil ao cliente final.

Assim, foi realizado um trabalho cujo resultado prático, concretizado a partir de outubro de 2011 e que vem se sustentando até a presente data, possibilitou ao LRF abastecer a linha de galvanização todos os meses sem a necessidade de complementação de bobinas oriundas de outros laminadores. Com isto, a planta de Araucária - PR tornou-se auto-suficiente em bobinas full-hard, além de se tornar apta a fornecer bobinas full-hard ao mercado externo com o excedente de produção alcançado, isso de forma sustentável, segura e com respeito aos seus colaboradores e ao meio-ambiente.

* Contribuição técnica ao $51^{\circ}$ Seminário de Laminação - Processos e Produtos Laminados e Revestidos, 28 a 31 de outubro de 2014, Foz do Iguaçu, PR, Brasil. 